\title{
Perbedaan nilai kekasaran permukaan hasil finishing dengan menggunakan batu Arkansas dan fine diamond bur pada komposit Nanofiller
}

\author{
Sheilla Fauzia Maretta ${ }^{{ }^{*}}$, Diani Prisinda ${ }^{1}$, Anna Muryani $^{1}$ \\ ${ }^{1}$ Departemen Konservasi Gigi, Fakultas Kedokteran Gigi, Universitas Padjadjaran, Indonesia \\ *Korespondensi: $\underline{\text { sheillafm9@gmail.com }}$
}

\begin{abstract}
ABSTRAK
Pendahuluan: Tahap akhir prosedur restorasi yaitu finishing dan polishing. Prosedur finishing perlu dilakukan dengan baik untuk menghasilkan kontur dan hasil restorasi yang optimal. Tujuan penelitian ini untuk mengetahui nilai kekasaran permukaan dari restorasi resin komposit nanofiller yang dilakukan finishing dengan batu Arkansas dan fine diamond bur. Metode: Jenis penelitian yang digunakan adalah eksperimental semu. Sampel penelitian yaitu komposit nanofiller berbentuk silinder dengan ukuran diameter $6 \mathrm{~mm}$ dan tinggi $3 \mathrm{~mm}$. Jumlah sampel adalah 32 buah yang dibagi menjadi dua kelompok. Kelompok pertama terdiri dari 16 sampel yang dilakukan finishing dengan batu Arkansas dan kelompok kedua dengan fine diamond bur. Kekasaran permukaan sampel diukur dengan alat uji Surface Roughness Tester. Analisis data menggunakan uji statistik T-Test Independent. Hasil: Rata-rata nilai kekasaran permukaan finishing batu Arkansas $0.59 \mu \mathrm{m}$ dan fine diamond bur $0.77 \mu \mathrm{m}$. Kelompok resin komposit nanofiller yang dilakukan finishing dengan fine diamond bur lebih kasar dibandingkan dengan batu Arkansas. Simpulan: terdapat perbedaan yang signifikan pada nilai kekasaran permukaan komposit nanofiller hasil finishing antara batu Arkansas dengan fine diamond bur.
\end{abstract}

Kata kunci: Kekasaran permukaan, finishing, batu Arkansas, fine diamond bur, nanofiller

\section{The surface roughness value of Nanofiller composite at different finishing between Arkansas stone with fine diamond bur}

\section{ABSTRACT}

Introduction: The final stages of the restoration procedure are finishing and polishing. The finishing procedure need to be done properly to produce optimum contour and restoration results. This study was conducted to determine the surface roughness value of nanofiller composite using Arkansas stone and fine diamond bur. Methods: This study is quasi experimental. Thirty two cylinders of nanofiller resin based composite samples (diameter $6 \mathrm{~mm}$ and height $3 \mathrm{~mm}$ ) were prepared. Those samples were divided into two groups. First sixteen samples were finished by Arkansas stone, the other sixteen were finished by fine diamond bur. Surface roughness was measured using Surface Roughness Tester. T-Test Independent was conducted to depict the data analysis. Result: The average surface roughness value of finished Arkansas stone is $0.59 \mu \mathrm{m}$ and fine diamond bur $0.77 \mu \mathrm{m}$. The result of this study shows statistically significant. It was found surface roughness finished by fine diamond bur was rougher than Arkansas stone. Conclusion: This study showed that statistically significant on surface roughness value of finishing nanofiller composite restoration between Arkansas stone with fine diamond bur.

Keywords: Surface roughness, nanofiller, finishing, Arkansas stone, fine diamond bur. 


\section{PENDAHULUAN}

Prevalensi karies gigi di Indonesia pada tahun 2007-2013 meningkat dari 43.4\% menjadi 53.2\%. ${ }^{1}$ Prevalensi karies yang tinggi tersebut menunjukkan bahwa diperlukan adanya perawatan restorasi untuk mengembalikan keadaan biologis, fungsional, dan estetika dari gigi tersebut. ${ }^{2}$ Kebutuhan estetika pada restorasi gigi dapat dipenuhi dengan penggunaan bahan restorasi komposit jenis terbaru yaitu komposit nanofiller. Kombinasi nanopartikel dan nanocluster pada komposit ini mengurangi jumlah ruang interstisial antar partikel filler sehingga memiliki sifat fisis yang lebih baik. ${ }^{3}$ Keberhasilan suatu restorasi dapat ditentukan oleh banyak faktor, salah satunya adalah prosedur pemolesan pada tahap akhir restorasi. ${ }^{4,5}$

Pemolesan merupakan salah satu cara untuk menghasilkan permukaan restorasi yang optimal. ${ }^{6}$ Tahap pertama dari prosedur pemolesan adalah prosedur finishing. ${ }^{6}$ Jenis alat poles yang lebih efektif digunakan pada tahap ini merupakan alat poles dengan permukaan yang kasar. ${ }^{7}$ Kesuksesan finishing dapat dicapai dengan penggunaan alat dan bahan yang sesuai dengan tahapannya yaitu mulai dari grit kasar hingga halus. ${ }^{7}$ Nilai kekasaran pada permukaan restorasi dapat berbeda bergantung pada alat poles yang digunakan. ${ }^{6,7}$

Alat yang digunakan pada tahap finishing diantaranya adalah batu Arkansas dan fine diamond bur. ${ }^{8}$ Persamaan kedua alat poles ini yaitu dapat digunakan untuk menghasilkan kontur gigi dan pola konsentris seragam pada permukaan serta memiliki kemampuan pengikisan yang baik. ${ }^{9}$ Kekurangan lain dari hasil poles batu Arkansas dapat mengurangi banyak struktur jaringan gigi yang tersisa. ${ }^{10}$ Prosedur finishing dengan fine diamond bur menghasilkan permukaan dengan sedikit goresan namun tidak merusak banyak struktur jaringan gigi yang tersisa. ${ }^{11}$

Batu Arkansas dan fine diamond bur populer digunakan sebagai alat finishing hingga saat ini. ${ }^{8}$ Hasil finishing dengan menggunakan kedua alat poles tersebut secara tunggal pada restorasi komposit jenis nanofiller belum ada penelitian nilai kekasaran permukaannya, tujuan penelitian ini adalah untuk mengetahui perbedaan nilai kekasaran permukaan hasil finishing batu Arkansas dengan fine diamond bur pada komposit nanofiller

\section{METODE}

Penelitian ini menggunakan metode kuasi eksperimental atau eksperimental semu. Sampel penelitian yaitu 32 buah komposit nanofiller berbentuk silinder dengan ukuran diameter $6 \mathrm{~mm}$ dan tinggi $3 \mathrm{~mm}$ yang terdiri dari 16 sampel yang dilakukan finishing dengan batu Arkansas dan 16 sampel dengan fine diamond bur, kekasaran permukaan sampel diukur dengan alat uji Surface Roughness Tester. Penelitian dilakukan pada FebruariMaret 2018, penelitian dilakukan di Laboratorium Terpadu RSGM Unpad dan Laboratorium Metrologi FTMD Institut Teknologi Bandung.

Prosedur penelitian dilakukan dengan persiapan, pembuatan 32 sampel resin komposit, prosedur finishing pada komposit, pengujian nilai kekasaran permukaan, serta pengolahan dan analisis data dengan T-Test Independent. Alat light curing komposit pada gambar 1 dilakukan kalibrasi terlebih dahulu pada tahap persiapan penelitian. Light curing komposit memiliki cahaya lebih dari $465 \mathrm{~mW} / \mathrm{mm}^{2}$ untuk memastikan bahan komposit terpolimerisasi sempurna oleh alat yang digunakan.

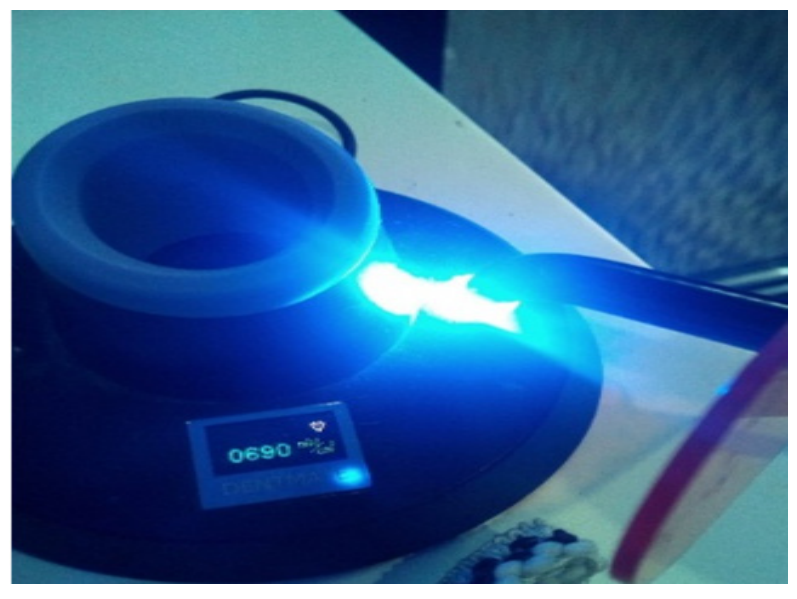

Gambar 1. Kalibrasi light curing unit

Pembuatan sampel resin komposit dilakukan dengan pembuatan mold terlebih dahulu. Mold dengan diameter $6 \mathrm{~mm}$ dan tinggi $3 \mathrm{~mm}$ diletakan di atas preparat glass yang telah dilapisi mylar strip kemudian sampel dibentuk dari cetakan lubang pada mold. Komposit nanofiller dimasukkan ke dalam cetakan selapis demi selapis $( \pm 1,5 \mathrm{~mm})$ kemudian diratakan dengan intrumen plastik komposit. Resin komposit dilakukan penyinaran dengan visible light curing yang telah dilakukan kalibrasi. Penyinaran dilakukan dua kali selama 20 detik dari arah atas 
dan samping sampel untuk mencapai polimerisasi sempurna. Komposit dimasukkan sampai memenuhi cetakan seperti gambar 2 kemudian dilakukan penyinaran kembali.

Mylar strips diletakkan kembali di atas resin komposit untuk memberikan permukaan yang rata dan menciptakan kondisi yang sama di semua sampel. Spesimen resin komposit dibuat sebanyak 32 buah dengan prosedur yang sama ditunjukkan pada gambar 3. Sampel komposit yang telah terbentuk dilepaskan dari cetakan kemudian didiamkan terlebih dahulu selama 3 menit selama proses polimerisasi.

Komposit yang telah tercetak direndam ke dalam aquades pada gelas ukur kemudian dimasukkan pada incubator dengan suhu $37^{\circ} \mathrm{C}$ selama 24 jam untuk mencapai polimerisasi sempurna dan menciptakan keadaan fisiologis rongga mulut.
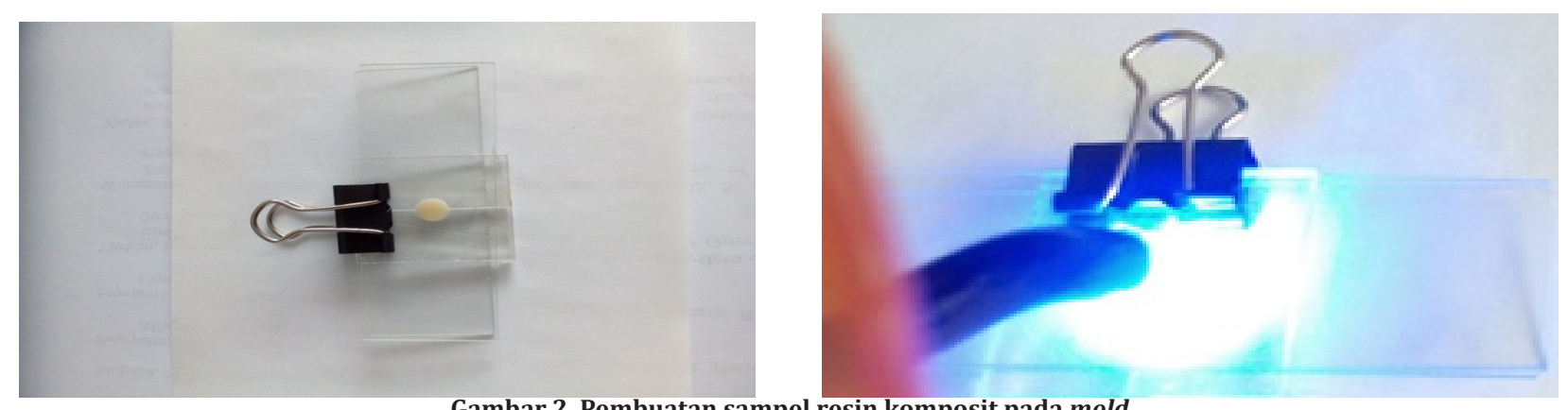

Gambar 2. Pembuatan sampel resin komposit pada mold

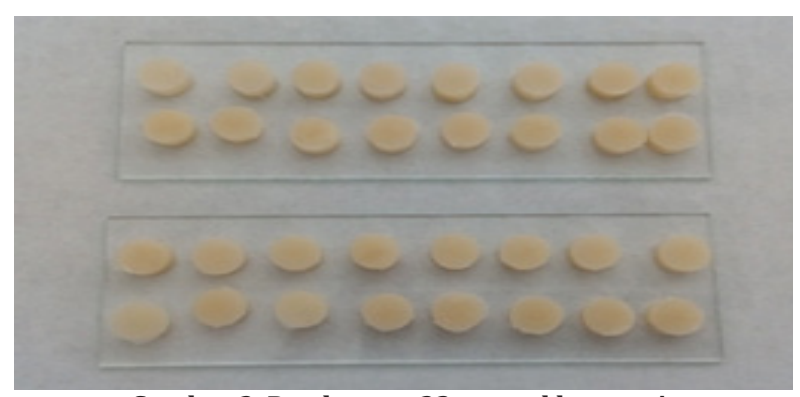

Gambar 3. Pembuatan 32 sampel komposit
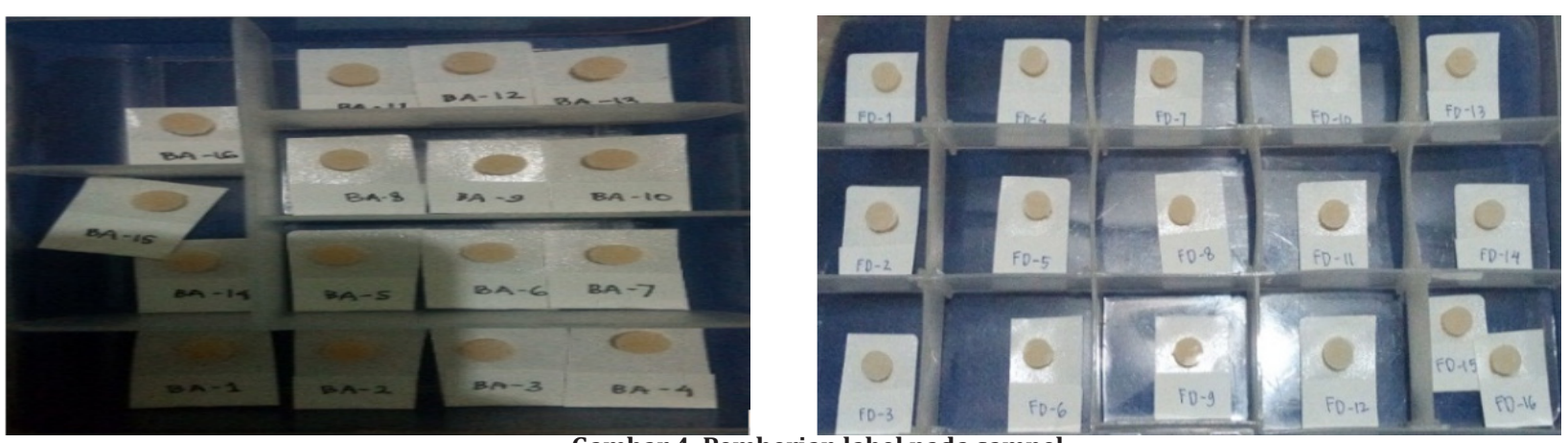

Gambar 4. Pemberian label pada sampel

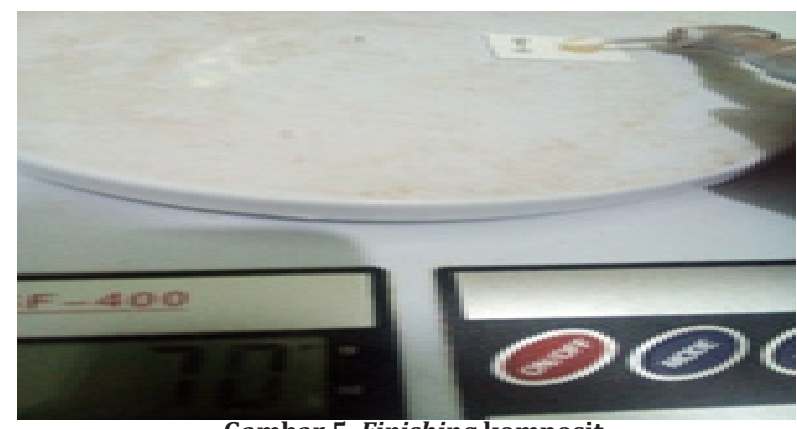

Gambar 5. Finishing komposit

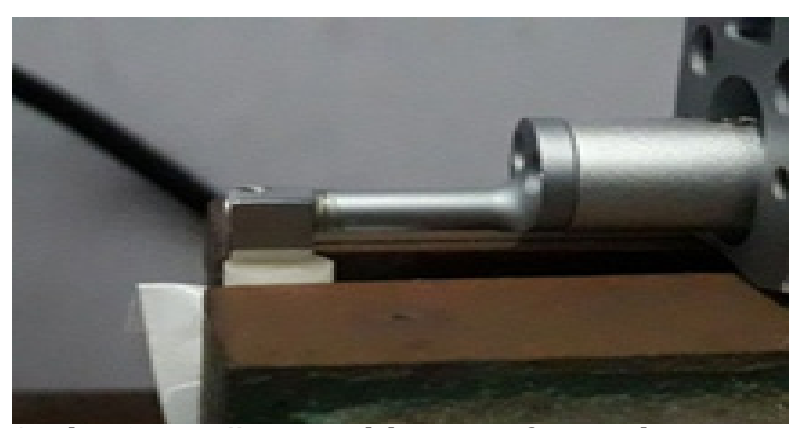

Gambar 6. Pengujian sampel dengan surface roughness tester 
Prosedur finishing dilakukan pada sampel yang seluruh permukaannya rata tertutup oleh mylar strip. Seluruh sampel diberi label kode seperti gambar 4. Kelompok pertama terdiri dari 16 buah resin komposit diberi label dengan kode BA1 hingga BA16. Kelompok kedua terdiri dari 16 buah resin komposit diberi label dengan kode FD1 hingga FD16. Kode BA merupakan kelompok komposit yang dilakukan finishing dengan batu Arkansas sedangkan kode FD menggunakan fine diamond bur. Setiap sampel dilakukan finishing dengan bur berbeda. Prosedur finishing dilakukan satu arah selama 20 detik dengan kecepatan mikromotor yang sama. Finishing dilakukan di atas timbangan digital (Gambar 5) agar tekanan yang diberikan pada setiap sampel terkontrol sama besar (massa pada timbangan menunjukkan angka 50-70 gram). Sampel pada gambar 5 merupakan sampel yang telah dilakukan finishing diletakkan posisi melintang di atas meja alat pengukur kekasaran permukaan (Surface Roughness Tester) hingga terdapat tanda pada layar monitor jika ujung jarum pengukur telah menyentuh permukaan sampel yang diukur. Tombol start ditekan kemudian alat bergerak dengan kecepatan $1 \mathrm{~mm} /$ detik. Pengukuran dilakukan 3 kali per sampel pada permukaan berbeda kemudian hasil pengukuran tersebut dirata-ratakan. Data hasil penghitungan dibuat seluruhnya dalam bentuk tabel Data dilakukan pengujian normalitas dengan Uji Kolmogorov-Smirnov dan Uji Shaphiro-Wilk dengan SPSS. Tabel yang berisi data nilai kekasaran permukaan dilakukan pengujian statistik dengan T-Test Independent sehingga didapatkan data yang signifikan mengenai perbedaan nilai kekasaran. Interpretasi SPSS disajikan dalam bentuk tabel kemudian dideskripsikan.

HASIL

Sampel penelitian dilakukan pengukuran sebanyak tiga kali pada tiga titik berbeda kemudian dihitung rata-ratanya. Nilai rata-rata tersebut dinyatakan dalam Ra dengan satuan mikrometer $(\mu \mathrm{m})$. Interpretasi data secara deskriptif pada tabel 1 menunjukkan nilai kekasaran permukaan dari 16 sampel

Resin komposit nanofiller hasil finishing batu Arkansas yaitu $0.59 \mu \mathrm{m}$. Nilai kekasaran permukaan pada tabel 2 menunjukkan rata-rata nilai kekasaran permukaan 16 sampel resin komposit nanofiller hasil finishing fine diamond bur yaitu 0.77 $\mu \mathrm{m}$. Hasil penelitian pada tabel 1 dan 2 menunjukkan bahwa nilai kekasaran permukaan resin komposit nanofiller hasil finishing fine diamond bur lebih besar dibandingkan dengan batu Arkansas.

Tabel 1. Rata-rata nilai hasil pengukuran kekasaran permukaan dengan fine diamond bur

\begin{tabular}{cc}
\hline Nampel & Nilai Kekasaran Permukaan $(\mu \mathrm{m})$ \\
FD1 & Fine diamond bur \\
FD2 & 0.69 \\
FD3 & 0.78 \\
FD4 & 0.89 \\
FD5 & 0.70 \\
FD6 & 0.77 \\
FD7 & 0.73 \\
FD8 & 0.89 \\
FD9 & 0.75 \\
FD10 & 0.74 \\
FD11 & 0.70 \\
FD12 & 0.85 \\
FD13 & 0.77 \\
FD14 & 0.82 \\
FD15 & 0.68 \\
FD16 & 0.83 \\
\hline Rata-Rata & 0.74 \\
\hline
\end{tabular}

Tabel 2. Nilai rata-rata hasil pengukuran kekasaran permukaan dengan batu arkansas

$\begin{array}{cc}\text { Sampel } & \text { Nilai Kekasaran Permukaan }(\boldsymbol{\mu m}) \\ \text { BA1 } & \text { Batu Arkansas } \\ \text { BA2 } & 0.58 \\ \text { BA3 } & 0.47 \\ \text { BA4 } & 0.60 \\ \text { BA5 } & 0.52 \\ \text { BA6 } & 0.49 \\ \text { BA7 } & 0.59 \\ \text { BA8 } & 0.49 \\ \text { BA9 } & 0.68 \\ \text { BA10 } & 0.62 \\ \text { BA11 } & 0.81 \\ \text { BA12 } & 0.63 \\ \text { BA13 } & 0.57 \\ \text { BA14 } & 0.58 \\ \text { BA15 } & 0.59 \\ \text { BA16 } & 0.53 \\ \text { Rata-Rata } & 0.66 \\ \end{array}$


Tabel 3. Uji normalitas data hasil penelitian

\begin{tabular}{ccc}
\hline Alat Finishing & Uji Kolmogorov-Smirnov & Uji Shapiro-Wilk \\
\hline & Probabilitas & Probabilitas \\
Fine Diamond Bur & 0.200 & 0.244 \\
Batu Arkansas & 0.200 & 0.210 \\
\hline
\end{tabular}

Tabel hasil pengujian normalitas di atas menunjukkan bahwa nilai signifikansi (probabilitas) uji Kolmogorov-Smirnov hasil finishing batu Arkansas dan fine diamond yaitu 0.200. Nilai signifikansi (probabilitas) uji Shapiro-Wilk hasil finishing batu Arkansas 0.210 dan fine diamond yaitu 0.244. Hasil yang didapat dari masing-masing kelompok pada uji Kolmogorov-Smirnov dan Shapiro-Wilk bernilai lebih dari 0.05 sehingga dapat disimpulkan bahwa data penelitian ini berdistribusi secara normal dan dapat digunakan untuk analisis parametrik lebih lanjut.

Hasil penghitungan data pada tabel 3 menunjukkan bahwa $t_{\text {hitung }}>t_{\text {tabel }}$ maka $\mathrm{H}_{0}$ ditolak dan $\mathrm{H}_{1}$ diterima, menunjukkan adanya perbedaan nilai kekasaran permukaan hasil finishing batu Arkansas dengan fine diamond bur pada komposit nanofiller.

Tabel 4. Hasil t-test independent

\begin{tabular}{cccccccc}
\hline Alat Finishing & $\mathrm{N}$ & Rata-Rata & Simpangan Baku & Standar Error Rata-Rata & $\begin{array}{c}\text { Probabiliti } \\
\text { (Sig.) }\end{array}$ & $\mathrm{t}_{\text {hitung }}$ & $\mathrm{t}_{\text {tabel }}$ \\
$\begin{array}{c}\text { Batu Arkansas } \\
\text { Fine diamond }\end{array}$ & 16 & 0.588 & 0.08463 & 0.02116 & 0.000 & 6.721 & 2.042 \\
$\quad$ bur & 16 & 0.770 & 0.06807 & 0.01702 & 0.000 & & \\
\hline
\end{tabular}

\section{PEMBAHASAN}

Penelitian ini menguji kekasaran permukaan 16 sampel resin komposit nanofiller yang dilakukan finishing dengan batu Arkansas (kode BA) dan 16 sampel resin komposit nanofiller yang dilakukan finishing dengan fine diamond bur (kode FD). Kekasaran permukaan resin komposit dihitung dengan menggunakan Profilometer atau Surface Roughness Tester Mitutoyo SJ-301. Pengukuran kekasaran permukaan yaitu dari goresan stylus diamond yang berjalan melintang searah dengan pemolesan sampel. Uji statistik mengenai hasil nilai $t_{\text {tabel }}$ dengan taraf kesalahan $\alpha=5 \%$ adalah 2.042 dan $t_{\text {hitung }}$ adalah 6.721. Perhitungan tersebut menunjukkan $t_{\text {hitung }}>t_{\text {tabel }}$ sehingga hipotesis $H_{1}$ diterima artinya terdapat perbedaan yang signifikan dari nilai kekasaran permukaan finishing restorasi resin komposit nanofiller antara batu Arkansas dengan fine diamond bur.

Prosedur finishing restorasi resin komposit memiliki peran penting dalam menghilangkan adanya oxygen-inhibited layer. ${ }^{12}$ Oxygen-inhibited layer merupakan monomer dan oligomer pada lapisan terluar komposit yang tidak terpolimerisasi akibat terperangkapnya oxygen saat proses light curing. ${ }^{13}$ Oxygen yang berkontak dengan komposit berdifusi dan menghambat reaksi polimerisasi dengan membentuk radikal bebas peroxide yang memiliki reaktivitas rendah. ${ }^{13}$ Komposisi oxygeninhibited layer sama seperti komposit yang tidak terpolimerisasi yaitu kental dan ikatan $\mathrm{C}=\mathrm{C}$ yang tidak bereaksi..$^{12,13}$

Permukaan restorasi dengan derajat polimerisasi lebih rendah dapat menyebabkan restorasi mudah mengalami diskolorisasi. ${ }^{6,14,15}$ Matriks resin lebih mudah menyerap air sehingga menyebabkan staining atau pewarnaan pada restorasi. ${ }^{15}$ Penghilangan oxygen-inhibited layer dengan prosedur finishing memiliki peran penting dalam mempertahankan resistensi terhadap perubahan warna dan kestabilan permukaan restorasi yang lebih baik. ${ }^{6}$ Prosedur finishing juga dapat menghilangkan adanya porositas akibat oxygen-inhibited layer. ${ }^{6}$

Kekasaran permukaan suatu restorasi dapat ditentukan oleh beberapa faktor diantaranya partikel bahan pengisi maupun bahan abrasif yang digunakan dalam prosedur finishing dan polishing. ${ }^{15}$ Alat finishing maupun polishing mengandung bahan abrasif yang berbeda-beda. ${ }^{15,16}$ Bahan abrasif suatu alat poles memiliki kekerasan yang beragam. Moh's Hardness merupakan skala kekerasan suatu bahan dengan rentang skala 1 hingga 10 . Angka 10 pada Moh's Hardness menunjukkan angka tertinggi dan memiliki sifat yang lebih keras. ${ }^{15}$ Komposit memiliki 
skala 5 - 7 Moh's. ${ }^{15}$ Bahan abrasif diamond pada fine diamond bur memiliki tingkat kekerasan sebesar 10 Moh's sedangkan aluminum oxide pada batu Arkansas adalah 9 Moh's. ${ }^{15}$ Tingkat kekerasan pada Moh's Hardness menentukan keefektivitasan kerja suatu alat finishing. ${ }^{17}$

Partikel bahan abrasif dengan kekerasan lebih tinggi menghasilkan permukaan yang lebih kasar. ${ }^{17}$ Prosedur pemolesan pada tahap finishing membutuhkan alat yang memiliki ukuran grit partikel abrasif paling kasar terlebih dahulu. ${ }^{15}$ Penggunaan partikel abrasif yang dilakukan sesuai urutannya memberikan keuntungan antara lain dapat meratakan keberadaan goresan yang lebih dalam, mengurangi material yang kasar lebih cepat, serta mengikis partikel filler secara merata. ${ }^{18}$ Hasil penelitian ini menunjukkan nilai kekasaran permukaan restorasi resin komposit nanofiller yang dilakukan finishing dengan fine diamond bur memiliki nilai rata-rata kekasaran permukaan 0.77 $\mu \mathrm{m}$ sedangkan dengan batu Arkansas menunjukkan nilai rata-rata kekasaran permukaan $0.59 \mu \mathrm{m}$. Penelitian ini sesuai dengan teori pada Gladwin and Bagby $^{16}$, bahwa hasil finishing oleh fine diamond bur dengan grit kekerasan yang lebih tinggi memberikan hasil yang lebih kasar dibandingkan dengan batu Arkansas.

Alat poles yang dapat dikategorikan sebagai alat polishing untuk menghasilkan permukaan kilap memiliki nilai kekasaran permukaan $<0.1$ $\mu$. $^{19}$ Nilai kekasaran permukaan restorasi resin komposit nanofiller yang dipoles dengan alat polishing sof-lex, super-snap, dan flexi-disk menunjukkan nilai kekasaran permukaan 0.058 $0.14 \mu \mathrm{m} .{ }^{19}$ Rata-rata nilai kekasaran batu Arkansas berdasarkan penelitian yang dilakukan ini yaitu $0.59 \mu \mathrm{m}$ artinya kekasaran permukaan restorasi resin komposit nanofiller yang dilakukan finishing dengan batu Arkansas lebih halus dari pada fine diamond bur. Hasil penelitian Moda ${ }^{19}$ menunjukkan bahwa walaupun batu Arkansas lebih halus dari fine diamond bur, batu Arkansas merupakan alat finishing dikarenakan memiliki kekasaran permukaan di atas kekasaran permukaan hasil pemolesan dengan alat polishing.

Nilai kekasaran permukaan di atas 0.1 $\mu \mathrm{m}$ dapat menyebabkan ketidaknyamanan pada indera tactile. ${ }^{20}$ Prosedur polishing dibutuhkan setelah prosedur finishing untuk menghilangkan ketidakteraturan permukaan akibat proses finishing dan menciptakan permukaan restorasi yang kilap. ${ }^{15}$ Restorasi yang halus dan kilap dapat mengurangi kemungkinan terjadinya akumulasi plak, karies sekunder, staining, maupun inflamasi gingiva. ${ }^{6,719,20}$ Fine diamond bur dan batu Arkansas keduanya merupakan alat finishing sehingga dibutuhkan alat polishing setelahnya untuk menciptakan hasil restorasi optimal yang dapat memberikan kenyamanan dan kesehatan rongga mulut dapat terjaga dengan baik. ${ }^{15,20-22}$

\section{SIMPULAN}

Simpulan penelitian ini adalah terdapat perbedaan nilai kekasaran permukaan hasil finishing batu Arkansas dengan fine diamond bur pada komposit nanofiller.sebesar $0.18 \mu \mathrm{m}$. Nilai rata-rata kekasaran permukaan dengan alat finishing fine diamond bur $0.77 \mu \mathrm{m}$ dan batu Arkansas $0.59 \mu \mathrm{m}$.

\section{DAFTAR PUSTAKA}

1. Riset Kesehatan Dasar (Riskesdas). Hasil Riskesdas 2013-Departemen Kesehatan Republik Indonesia. Jakarta: Balitbang Kemenkes RI. 2013. [disitasi pada 30 Oktober 2017] Diakses dari: http://www.depkes.go.id/resource/ download/general/Hasil\% 20Riskesdas $\% 20$ 2013.pdf

1. Abzal, M.S.; M. Rathakrishnan; V. Prakash; P. Vivekanandhan; A. Subbiya; and V. G. Sukumaran. Evaluation of surface roughness of three different composite resins with three different polishing systems. J Conserv Dent 2016; 19(2):171.

3. Yadav, R.D.; D. Raisingani; D. Jindal; and R. Mathur. A comparative analysis of different $\mathrm{fi}$ nishing and polishing devices on nanofilled, microfilled, and hybrid composite: a scanning electron microscopy and profilometric study. Int J Clin Pediatr Dent 2016; 9(3):201.

2. Heymann, H. O.; E. J. Swift; and A. V. Ritter. Sturdevant's Art and Science of Operative Dentistry. Elsevier Health Science 2014; Pp. 141-142.

3. Rai and Gupta. In vitro evaluation of the effect of two finishing and polishing systems on four esthetic restorative materials. J Conserv Dent 2013; 16(6):564.

4. Kumari, C.M.; K. M. Bhat and R. Bansal. 
Evaluation of surface roughness of different restorative composites after polishing using atomic force microscopy. J Conserv Dent 2016; 19(1):56.

5. Scheibe; Almeida; I. S. Medeiros; I. F.

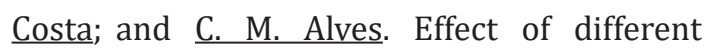
polishing systems on the surface roughness of microhybrid composites. LAppl Oral Sci 2009; 17(1): 21-26.

6. Nair, et al. Three-dimensional evaluation of surface roughness of resin composites after finishing and polishing. J Conserv Dent 2016; 19(1):91.

7. Clarke; A. Aquilla; L.E. Bertassoni; M. Guazzato; I. Klineberg. Surface roughness of restoration margin preparations: a comparative analysis of finishing techniques. Int $J$ Periodontics Restorative Dent 2015;35(2):211.

8. Türkün, L.S. and M. Türkün. The effect of one step polishing system on the surface roughness of three esthetic resin composite materials. $J$ Oper Dent 2004; 29 (2):203-211.

9. Botta, A.C.; S. Duarte; F. Paulin; and S.M. Gheno. Effect of dental finishing instruments on the surface roughness of composite resins as elucidated by atomic force microscopy. Microscopy and Microanalysis 2008; 14(05):380-386.

10. Rinastiti, M.; M. Özcan; W. Siswomihardjo and H.J. Busscher. Immediate repair bond strengths of microhybrid, nanohybrid and nanofilled composites after different surface treatments. JOD 2010; 38(1) Pp.29-38.

11. Ghivari, S.; M. Chandak; and N. Manvar. Role of oxygen inhibited layer on shear bond strength of composites. J Conserv Dent 2010; 13:39-41

12. Kameyama, et al. Influence of finishing/ polishing procedures on the surface texture of two resin composites. Open Dent J 2008; 2:56.

13. Anusavice, K. J. Phillip's Science of Dental Material. 10th, ed. W. B. Saunders Company. St. Louis. 2003; Pp. 277-278, 298-299, 351-375, 399-439.

14. Gladwin and Bagby. Clinical Aspects of Dental Materials. Philadelphia: Lippincott Williams \& Wilkins. 9th Edition 2008; Pp. 195-220.

15. Sen. Goller, H. Issever. The effect of two polishing pastes on the surface roughness of bis-acryl composite and methacrylate-based resins. J Prosthet Dent 2002; 88(5): 527-532.

16. Sakaguchi, R. L., and Powers, J. M. Craig's Restorative Dental Materials. Elsevier Health Sciences 2011; Pp. 161-177.

17. Moda, M.D., et al. Comparison of different polishing methods on the surface roughness of microhybrid, microfill, and nanofill composite resins. Journal of investigative and clinical dentistry 2017; 9(1), p.e12287.

18. Jones C.S., Billington, Pearson. The in vivo perception of roughness of restorations. Braz Dent J 2004; 196:42-5.

19. Koh, et al. Finishing systems on the final surface roughness of composites. J Contemp Dent Pract 2008; 9(2):138-145.

20. Jefferies, S. R. Abrasive finishing and polishing in restorative dentistry: a state-of-the-art review. Dent Clin North Am 2007; 51(2):379397. 